\title{
Aromatic potential of Bordeaux grape cultivars: Identification and assays on 4-oxononanoic acid, a $\gamma$-nonalactone precursor
}

\author{
Philippine de Ferron, Cécile Thibon, Svitlana Shinkaruk, Philippe Darriet, Lucille \\ Allamy and Alexandre Pons
}

Univ. Bordeaux, INRAE, Unite de recherche CEnologie, EA 4577, USC 1366 INRAE, ISVV, 33882

Villenave d'Ornon cedex, France

Corresponding author:

Cécile Thibon: cecile.thibon@u-bordeaux.fr

ORCID: 0000-0001-9259-5176

Univ. Bordeaux, INRAE, Unite de recherche CEnologie, EA 4577, USC 1366 INRAE, ISVV, 33882

Villenave d'Ornon cedex, France

Philippine de Ferron: philippine.de-ferron@u-bordeaux.fr

ORCID: 0000-0002-8833-1802

Univ. Bordeaux, INRAE, Unite de recherche CEnologie, EA 4577, USC 1366 INRAE, ISVV, 33882

Villenave d'Ornon cedex, France

Svitlana Shinkaruk: svitlana.poix@u-bordeaux.fr

ORCID: 0000-0002-8150-0001

Univ. Bordeaux, INRAE, Unite de recherche CEnologie, EA 4577, USC 1366 INRAE, ISVV, 33882

Villenave d'Ornon cedex, France

Univ. Bordeaux, CNRS, Bordeaux INP, ISM, UMR 5255, 33400 Talence, France

Philippe Darriet : philippe.darriet@u-bordeaux.fr

ORCID: 0000-0002-7202-8710

Univ. Bordeaux, INRAE, Unite de recherche CEnologie, EA 4577, USC 1366 INRAE, ISVV, 33882

Villenave d'Ornon cedex, France

Lucile Allamy: lucile.allamy@u-bordeaux.fr

ORCID: 0000-0001-8491-0834

Univ. Bordeaux, INRAE, Unite de recherche CEnologie, EA 4577, USC 1366 INRAE, ISVV, 33882

Villenave d'Ornon cedex, France

Alexandre Pons: alexandre.pons@u-bordeaux.fr

ORCID: 0000-0002-0345-8186

Univ. Bordeaux, INRAE, Unite de recherche CEnologie, EA 4577, USC 1366 INRAE, ISVV, 33882

Villenave d'Ornon cedex, France

Seguin Moreau France, Z.I. Merpins, B.P. 94, F-16103 Cognac, France 


\section{Supporting Information}

\section{List of supplementary information:}

SI 1. 4-oxononanoic acid mass spectrometer in negative chemical ionization. NL: 5.97E8

(Results and Discussion paragraph 2)

SI 2. Impact of 4-oxononanoic acid supplementation in a red grape must organic extract analyzed by GC-NCI-MS with ammonia as reagent gas ( $m / z$ 171). Control (yellow), $30 \mu \mathrm{g} / \mathrm{L}$ (grey), $50 \mu \mathrm{g} / \mathrm{L}$ (orange) and $70 \mu \mathrm{g} / \mathrm{L}$ (blue).

(Results and Discussion paragraph 2)

SI 3. 4-oxononanoic acid assay performance according to sample preparation techniques

(Results and Discussion paragraph 2) 
Supplementary information 1.

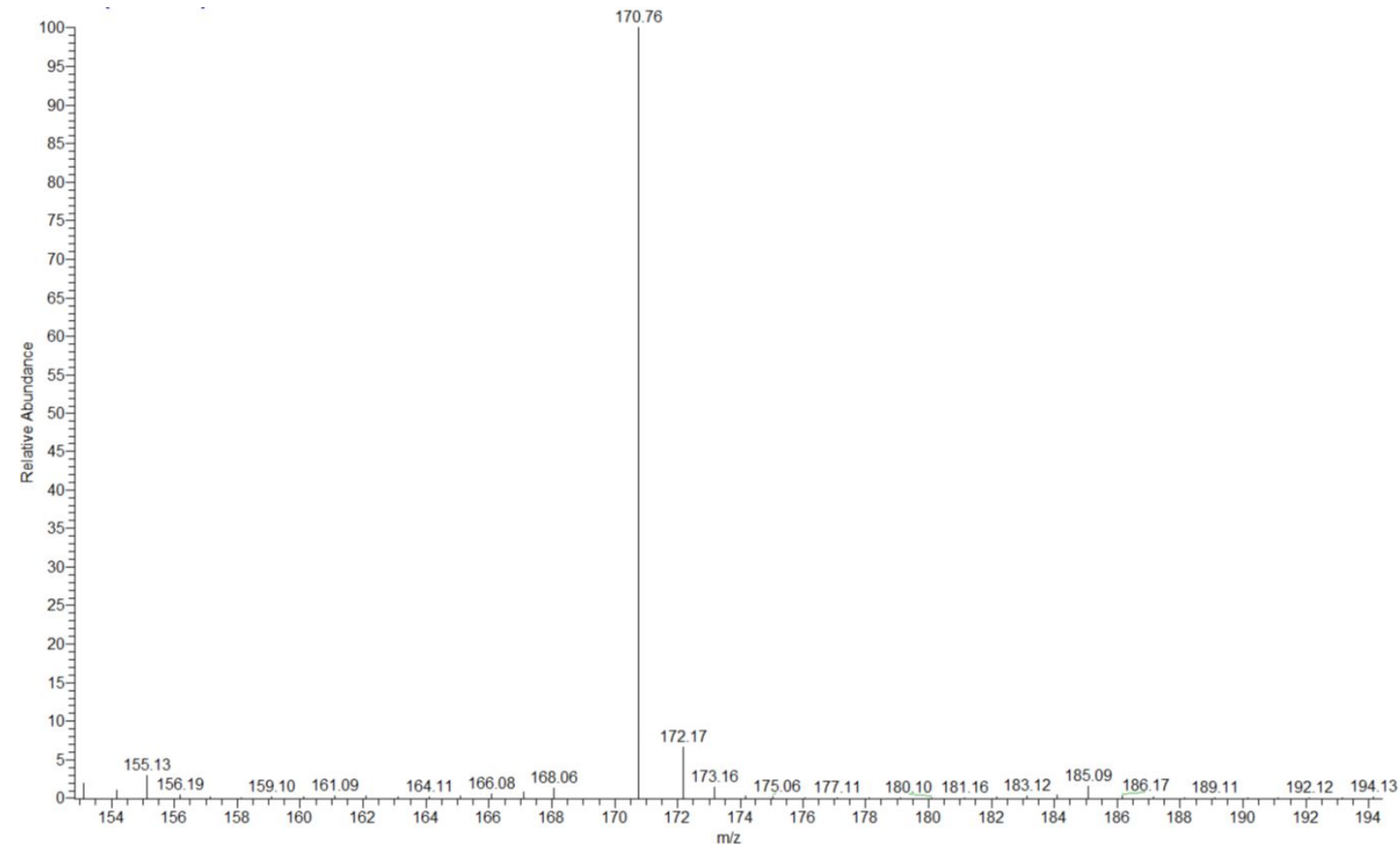


Supplementary information 2.

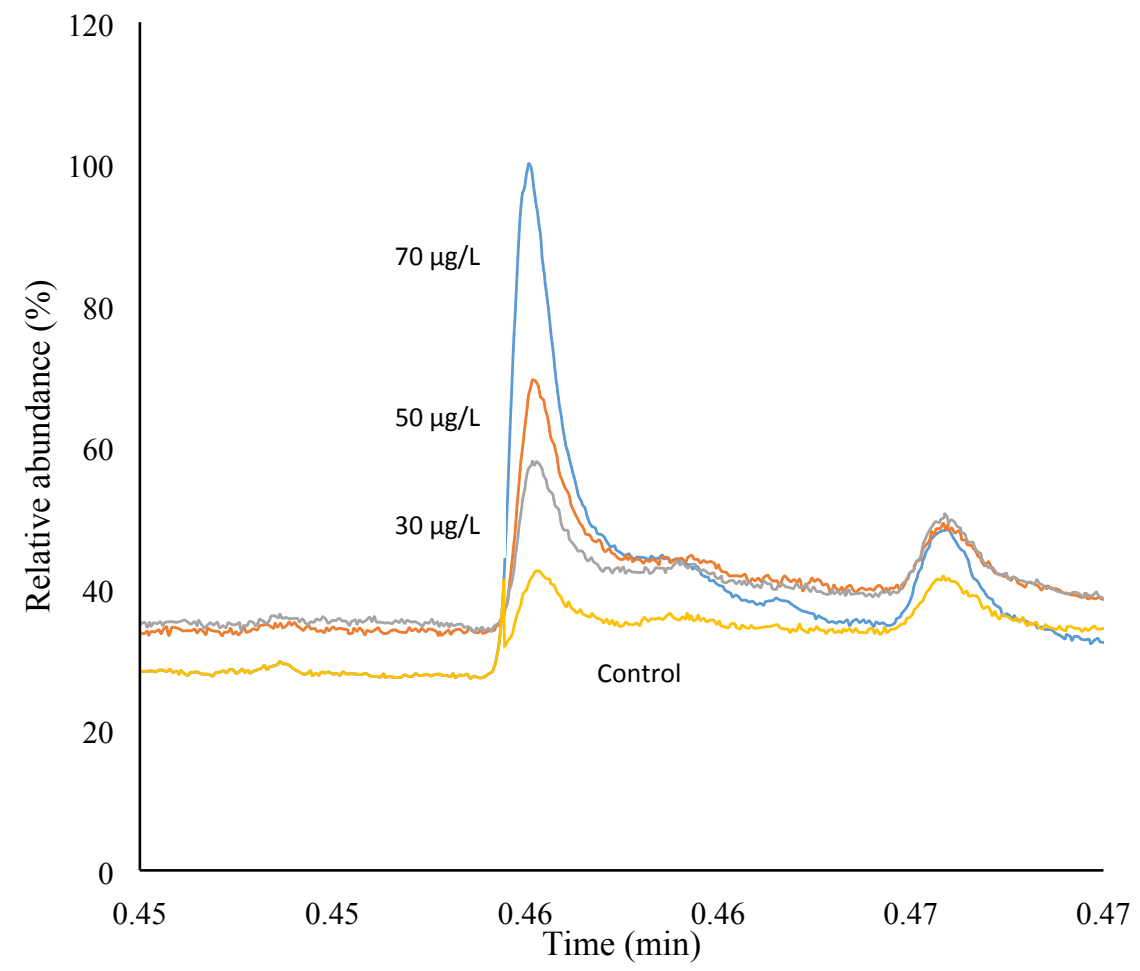


Supplementary information 3:

\begin{tabular}{cccc}
\hline $\begin{array}{c}\text { Sample } \\
\text { preparation } \\
\text { (volume) }^{\mathrm{a}}\end{array}$ & LOD $(\mu \mathrm{g} / \mathrm{L})^{\mathrm{b}}$ & ${\text { LOQ }(\mu \mathrm{g} / \mathrm{L})^{\mathrm{b}}}^{\mathrm{b}}$ & $\mathbf{R}^{\mathbf{2}}$ \\
\hline SPE $(10 \mathrm{~mL})$ & 2.67 & 8.90 & 0.9895 \\
$\mathrm{LLE}(100 \mathrm{~mL})$ & 1.26 & 4.39 & 0.9895 \\
LLE $(50 \mathrm{~mL})$ & 1.33 & 4.45 & 0.9907 \\
\hline
\end{tabular}

a commercial red grape juice samples spiked with commercial solution of 4-oxononanoic acid. ${ }^{a}$ limit of detection, ${ }^{b}$ limit of quantification; $L O D$ and $L O Q$ calculated from $S / N$ ratio of six points of each regression scale (from 2.5 to $50 \mu g / L, n=2$ ) 